\title{
NILAI SOSIAL NOVEL KELIR SLINDET KARYA KEDUNG DARMA ROMANSHA BERDASARKAN TINJAUAN SOSIOLOGI SASTRA SEBAGAI UPAYA MEMILIH BAHAN AJAR SASTRA DAN METODE PEMBELAJARANNYA
}

\author{
Eny Tarsinih \\ Prodi Pendidikan Bahasa dan Sastra Indonesia \\ Universitas Wiralodra \\ e-mail: enytarsinih18@gmail.com
}

\begin{abstract}
ABSTRAK
Latar belakang masalah penelitian ini sebagai berikut: (1) Pemahaman nilai-nilai sosial dapat dijadikan sebagai pandangan dan tolak ukur membandingkan baik buruknya kualitas suatu masyarakat yang berada di sekeliling peserta didik; (2) Peserta didik mampu memahami keadaan sosial di sekitarnya; (3) Pembelajaran analisis novel kurang bervariasi masih banyak mengkaji unsur intrinsiknya saja; (4) Penerapan model pembelajaran yang kurang digandrungi oleh kebanyakan peserta didik.

Berdasarkan latar belakang masalah di atas, rumusan masalah penelitian ini adalah: (1) Bagaimana struktur novel Kelir Slindet karya Kedung Darma Romansha? (2) Bagaimana nilai-nilai sosial yang terdapat dalam novel Kelir Slindet karya Kedung Darma Romansha? (3) Apakah Novel Kelir Slindet Karya Kedung Darma Romansha layak dijadikan alternatif bahan ajar sastra di SMP atau SMA? (4) Bagaimanakah model pembelajaran yang dapat digunakanuntuk novel Kelir Slindet karya Kedung Darma Romansha dalam menyampaikan pembelajaran sastra?

Metode penelitian yang digunakan adalah metode deskriptif kualitatif. Metode kualitatif adalah metode penelitian yang berlandaskan pada filsafat post-positivisme, digunakan untuk meneliti pada objek yang alamiah. Penulis memilih metode ini karena sumber datanya sudah tersedia tanpa harus melakukan perlakuan (treatment).

Berdasarkan hasil penelitian dapat disimpulkan, struktur intrinsik dalam novel Kelir Slindet Karya Kedung Darma Romansha memuat tema utama mengenai percintaan; alur yang terdapat pada novel adalah alur campuran; latar novel Kelir Slindet Karya Kedung Darma Romansha bertempat di Cikedung, perkampungan, musholla, panggung, dan balai desa, serta berlatar waktu malam, sore, siang; secara umum amanat yang terkandung dalam novel Kelir Slindet Karya Kedung Darma Romansha adalah kita harus pandai dalam menyikapi hidup, lingkungan punya pengaruh besar, jadilah manusi yang berprinsip kuat; nilai sosial dalam novel Kelir Slindet Karya Kedung Darma Romansha tentang persahabatan, kekompakan, persatuan, kepercayaan, keberagaman, gotong royong. Novel Kelir Slindet Karya Kedung Darma Romansha layak sebagai bahan ajar sastra berdasarkan tinjauan sosiologi sastra dan segi bahasa yang mudah dipahami, serta latar belakang kebudayaan yang hampir sama persis dengan kehidupan sehari-hari dan bukan hal baru bagi mereka.
\end{abstract}

Kata kunci: Nilai-nilai sosial, novel Kelir Slindet karya Kedung Darma Romansha, sosiologi sastra, bahan ajar, dan metode pembelajaran. 


\section{PENDAHULUAN}

Sastra merupakan sebuah refleksi miniatur kehidupan manusia.Sastra dapat diartikan sebagai suatu tulisan atau kata-kata yang mempunyai nilai seni dan budaya serta keindahan dengan makna tertentu. Sastra hadir sebagai hasil perenungan terhadap fenomena yang ada, berguna untuk manusia, kebudayaan, serta zaman. Karya sastra menjadi bagian yang tak terpisahkan dalam sejarah peradaban manusia, karya sasta dituding paling bertanggungjawab atas pola pikir seseorang dalam mengartikan dan memahami sesuatu, ini tidak lepas dari karya sastra yang merupakan suatu bentuk dan hasil pekerjaan seni kreatif yang objeknya adalah manusia dan kehidupannya dengan menggunakan bahasa sebagai mediumnya. Dalam hal ini dapat direalisasikan bahwa perlu jutaan imajinasi yang terkonsep sedari dini dalam diri manusia untuk menciptakan karya sastra kreatif, mengingat karya sastra yang hakikatnya dibangun oleh dua unsur yaitu intrinsik dan ekstrinsik.

Karya fiksi memiliki pemahaman yang lebih mendalam, bukan hanya sekadar cerita khayalan atau angan dari pengarang saja, melainkan wujud dari kreatifitas pengarang dalam menggali dan mengolah gagasan dalam pikirannya. Nurgiyantoro (2010:03) menyatakan bahwa karya sastra yang bersifat imajinatif, dapat dibagi dalam tiga jenis (genre) yaitu, prosa, puisi, dan drama.Yang berbentuk prosa biasanya berupa fiksi.

Karya sastra dapat membukakan mata pembaca untuk mengetahui realitas sosial, politik dan budaya dalam bingkai moral dan estetika, maka tidak heran jika karya sastra tidak dapat dianggap sebagai refleksi dari kehidupan nyata, akan tetapi karya sastra dapat pula dianggap representasi kenyataan hidup. Keterbatasan masyarakat dalam memahami sastra sangatlah minim, bahkan minat untuk melestarikannya pun sangatlah jauh dari kata patut. Sastra lokal daerah yang tak ternilai harganya dari waktu ke waktu kian terpinggirkan dan tak berbekas. Pengaruh budaya dan kebiasaan mengubah pola pikir masyarakat begitu kuat. Keperihatinan disertai harapan ini muncul seketika dengan penuh kesadaran dan didasari atas perlunya melestarikan sastra dan budaya yang kita warisi hingga saat ini. Dari dulu sampai sekarang karya sastra tidak pernah pudar dan mati, dalam kenyataannya karya sastra dapat dipakai untuk mengembangkan wawasan berpikir bangsa. Dengan demikian tidak mengherankan jika di awal-awal kemerdekaan bangsa ini banyak melahirkan penulis-penulis serta sastrawan produktif nan imajinatif.

Di satu pihak, melalui karya sastra masyarakat dapat menyadari bahwa merekalah yang bertanggung jawab terhadap 
perubahan diri mereka sendiri.Sebagai konsekuensinya, selain merupakan karya sastra yang imajiner, fiksi menawaran karya sastra dengan berbagai genre yang hadir meramaikan perkembangannya. Berbagai genre yang ada merupakan hasil kreasi dan imajinatif sastrawan yang dituangkan dalam bentuk karya sastra sesuai dengan pandangannya.

Karya sastra merupakan wujud gagasan melalui pandangan terhadap lingkungan sosial yang berada di sekelilingnya dengan menggunakan bahasa yang indah. Karya sastra dan tata nilaimerupakan dua fenomena sosial yang saling melengkapi dalam hakikat mereka sebagai suatu yang eksistensial. Sastra sebagai produk kehidupan mengandung nilai-nilai sosial serta nilai-nilai kehidupan manusia dalam arti total.

Novel adalah suatu karya sastra yang dapat dikaji dari unsur intrinsik dan ekstrinsik. Unsur intrinsik merupakan unsur utama yang membangun novel dari dalam, bisa dikatakan bahwa unsur intrinsik adalah unsur dalam cerita itu sendiri seperti tema, tokoh penokohan, alur, latar, sudut pandang, gaya bahasa, dan amanat. Sedangkan unsur ekstrinsik ialah unsur yang membangun novel dari luar seperti nilai-nilai sosial, moral, budaya dan estetika. Novel merupakan sebuah uraian mendalam tentang suatu tema yang diungkapkan lewat cerita kehidupan seseorang dengan orang-orang di sekitarnya. Novel merupakan rangkaian dari beberapa konflik yang membentuk satu jalan cerita. Di sisi lain sebuah karya sastra harus merupakan peneladanan alam semesta dan sekaligus merupakan model kenyataan dan jauh dari dunia ide. Nurgiyantoro (2009: 25) mengemukakan bahwa dunia kesastraan juga mengenal karya sastra yang berdasarkan cerita atau realita.

Secara institusional, obejek sosiologi dan sastra adalah manusia dan masyarakat. Sastra memanfaatkan pikiran, intelektualitas, tetapi tetap didominasi oleh emosionalitas. Tujuan sosiologi sastra adalah meningkatkan pemahaman terhadap sastra dalam kaitannya dengan masyarakat, menjelaskan bahwa rekaan tidak berlawanan dengan kenyataan.Karena itu, sesungguhnya sosiologi dan sastra itu memperjuangkan masalah yang sama. Dari uraian tersebut dapat ditarik kesimpulan bahwa antara masyarakat, kebudayaan, dan sastra merupakan suatu jalinan yang kuat, antara yang satu dengan yang lainnya saling memberi pengaruh, saling membutuhkan, dan saling menentukan dalam pertumbuhan dan perkembangannya.

\section{KERANGKA TEORI}

\section{Landasan Teori}

Untuk dapat menyelenggarakan kegiatan belajar sastra dengan baik, mutlak diperlukan sejumlah bahan ajar yang 
mumpuni serta relevan dari segi untuk dipecahkan di dalam masyarakat. Jadi, kesusastraannya dan segi psikologisnya. apabila pembelajaran sastra dilaksanakan Pemilihan karya sastra yang tidak main-main akan mampu merealisasikan tercapainya tujuan pengajaran sastra tentunya dengan disertai metode pembelajaran yang baik, disamping membantu siswa dalam proses belajar mengajar. Karya sastra mempunyai relevansi dengan masalah-masalah dunia pendidikan dan pengajaran, sebab itu sangat keliru bila dunia pendidikan selalu menganggap bidang eksakta lebih utama, lebih penting dibandingkan dengan ilmu sosial atau ilmu-ilmu humaniora.

Melalui pengajaran sastra, siswa diberi kesempatan untuk mengelaborasi pengalaman orang lain dalam menyelesaikan masalah kehidupan mereka. Dalam pembelajaran apresiasi sastra guru harus dapat memilih pembelajaran sastra dengan tepat. Rahmanto (2005: 16-24) bahwa pengajaran sastra dapat membantu pendidikan secara utuh apabila cakupannya meliputi empat manfaat, yaitu membantu keterampilan berbahasa, meningkatkan pengetahuan budaya, mengembangkan cita rasa, dan menunjang pembentukan watak.Selanjutnya, Rahmanto (1988: 15) menyatakan jika pembelajaran sastra dilakukan dengan cara yang tepat, maka pembelajaran sastra dapat memberikan sumbangan yang besar untuk memecahkan masalah-masalah nyata yang cukup sulit tanpa ada ketepatan antara bahan dan kondisi siswa, maka pembelajaran akan mengalami kegagalan.

Dalam pembelajaran sastra, guru tidak mengimplementasikannya secara instan terhadap siswa, guru berada di garda terdepan dalam memberikan apresiasi karya sastra dan menyadari betapa besarnya manfaat karya sastra bagi siswa. Guru harus bisa berkampanye terprogram secara terus menerus terhadap pentingnya sastra bagi peserta didik. Bahan pembelajaran sastra sudah termuat dalam kurikulum bahasa Indonesia, di dalamnya dijelaskan bahwa selain melestarikan nilai-nilai peradaban bangsa juga mendorong penciptaan masyarakat modern yang beradab dan memanusiakan manusia serta memperkenalkan nilai-nilai kemanusiaan yang universal, melatih kecerdasan emosional dan mempertajam daya pikir. Berdasarkan uraian tersebut, penulis terdorong untuk melakukan kajian terhadap nilai-nilai sosial novel Kelir Slindet karya Kedung Darma Romansha berdasarkan tinjauan sosiologi sastra sebagai upaya memilih bahan ajar sastra dan metode pembelajarannya.

\section{METODE PENELITIAN}

Metode penelitian yang digunakan 
dalam penelitian ini adalah metode deskriptif kualitatif. Metode kualitatif adalah metode penelitian yang berlandaskan pada filsafat post-positivisme, digunakan untuk meneliti pada objek yang alamiah (Sugiyono, 2011: 9). Penulis memilih metode ini karena sumber datanya sudah tersedia tanpa harus melakukan perlakuan (treatment).

Berdasarkan metode tersebut, penulis akan menganalisis unsur-unsur intrinsik dan ekstrinsik berupa nilai-nilai sosial yang terdapat dalam novel Kelir Slindet Karya Kedung Darma Romansha. Kemudian hasil analisis tersebut akan dikaitkan dengan kriteria pemilihan bahan pembelajaran sastra di SMA dan penerapan model pembelajarannya di SMA.

\section{SIMPULAN}

Berdasarkan analisis dan pembahasan novel Kelir Slindet karya Kedung Darma Romansha, penulis dapat menyimpulkan sebagai berikut.

1) Struktur novel Kelir Slindet karya

Kedung Darma Romansha

Tema dalam novel Kelir Slindet karya Andi Kedung Darma Romansha yaitu percintaan, tentang perjalanan perempuan yang dikagumi banyak lelaki. Tokoh utama dan tokoh tambahan dalam novel Kelir Slindet karya Kedung Darma Romansha yaitu Safitri sebagai tokoh utama. Safitri adalah orang yang baik, penuh kepedulian. Ia adalah sosok yang tabah, bersahabat, dan bersahaja. Sedangkan tokoh tambahan dalam novel Kelir Slindet yaitu Mukimin, Musthafa, Saritem, Sukirman, H. Nasir, Didi. Novel Kelir Slindet menggunakan alur campuran karena dalam novel tersebut bercerita tentang kejadian dan kebiasaan masyarakat terdahulu sebelumnya bahkan jauh sebelum Safitri dilahirkan. Selanjutnya, latar dalam novel tersebut yaitu latar tempat, latar waktu, dan latar sosial. Amanat dalam novel Kelir Slindet karya Andi Kedung Darma Romansha yaitu jadilah manusia yang memiliki keyakinan teguh, pandai menyikapi segala hal, yang perlu kita sadari adalah bahwa pendidikan merupakan investasi terbesar dalam hidup.

2) Nilai-nilai sosial dalam novel Kelir Slindet karya Kedung Darma yaitu sebagai berikut.

a) Persahabatan tergambar oleh sosok Mukimin yang siap berkorban demi keutuhan pertemanannya, begitu pun sebaliknya. Mukimin yang rela melakukan apa saja demi kebersamaan mereka. Teman yang selalu ada di setiap waktu.

b) Kerukunan tergambar pada tokoh Musthafa bersama anak-anak didik 
musholanya. Kebiasaan yang sudah terjalin sedari dulu masih dipertahankan dan dikelola oleh Musthafa. Kebiasaan mengaji di mushola sehabis petang tiba disertai dengan tingkah mereka yang bervariasi satu sama lain.

c) Keperdulian tergambar pada Safitri melalui masyarakat secara keseluruhan. Hal tersebut terbuktikan bahwa masyarakat selalu menanggapi dan peduli terhadap apa yang terjadi pada Safitri.

d) Persatuan dan kekompakan tergambar pada masyarakat luas. Dengan disimbolkan melalui kebiasaan turun-temurun dalam masyarakat, yaitu Upacara Mapag Sri.

e) Kepercayaan tergambar pada sikap masyarakat dalam menilai Musthafa. Mereka mempercayakan Musthafa sebagai pembimbing anak-anak mereka.

f) Keberagaman tergambar pada keseluruhan masyarakat dalam kebiasaan lama menyambut datangnya pencalonan Kepala Desa. Mereka dengan sikapnya tersendiri akan saling berlomba-lomba.

3) Novel Kelir Slindet karya Kedung Darma Romansha layak dijadikan sebagai bahan ajar sastra di SMA. Hal ini dapat dilihat dari segi makna tersirat maupun tersurat novel Kelir Slindet mengandung nilai-nilai bahasa yang beragam, karena terdapat gaya bahasa dan kosakata dengan tuturan yang dapat dipahami siswa pada umumnya, perkembangan jiwa (psikologi) novel Kelir Slindet mengandung banyak pesan yang baik bagi siswa, dan latar belakang budaya novel Kelir Slindet karya Kedung Darma Romansha menggambarkan pandangan hidup seseorang yang baik bagi pembelajaran siswa. Oleh karena itu, novel Kelir Slindet karya Kedung Darma Romansha layak dijadikan sebagai bahan ajar sastra di SMA.

4) Model yang digunakan dalam pembelajaran novel Kelir Slindet karya Kedung Darma Romansha di SMA yaitu model pembelajaran Investigasi Kelompok (Group Investigation). Model pengajaran ini dapat membuat siswa lebih aktif dan lebih leluasa untuk berinteraksi dengan temannya karena model pengajaran ini menggunakan metode diskusi kelompok. Keterlibatan dengan orang lain akan membuka kesempatan bagi siswa untuk memperbaiki pemahaman terhadap materi yang telah disampaikan. 
5) Karya sastra lokal setidaknya mampu diterima di tengah-tengah masyarakat dan cukup mendapat tempat. Kandungan novel Kelir Slindet yang banyak memiliki kesamaan dengan penerapan kehidupan sehari-hari di tengah masyarakat dinilai menjadi aspek menarik.

\section{Saran}

Berdasarkan hasil analisis terhadap novel Kelir Slindet karya Kedung Darma Romansha, peneliti dapat memberikan saran sebagai berikut.

1) Nilai sosial yang ada pada tiap tokoh maupun masyarakat secara keseluruhan dalam novel, hendaknya diajarkan sesuai dengan perkembangan psikologi siswa. Agar siswa mampu mengembangkan rasa keingintahuannya terhadap sebuah perbuatan yang berakibat baik atau buruk bagi dirinya.

2) Guru Bahasa Indonesia hendaknya dapat menciptakan kegiatan belajar mengajar yang efektif dan menyenangkan, pemilihan bahan ajar yang dekat dan disenangi siswa. Dalam hal ini novel Kelir Slindet karya Kedung Darma Romansha dapat dijadikan bahan ajar sastra di SMA.

3) Nilai sosial dalam novel Kelir Slindet karya Kedung Darma Romansha sesuai untuk dijadikan bahan ajar sastra di
SMA.

4) Guru hendaknya memilih model pembelajaran yang tepat dan sesuai dengan materi yang akan diajarkan, agar tujuan pembelajaran tercapai.

5) Masyarakat hendak lebih mencintai dan melestarikan sastra lokal daerahnya secara keseluruhan sebagai nilai eksotik yang berharga dan tak tergantikan.

\section{DAFTAR PUSTAKA}

Nurgiyantoro, Burhan. 2010. Penilaian Pembelajaran Bahasa Berbasis Kompetensi. Yogyakarta: BPFE YOGYAKARTA.

Sugiyono. 2011. Metode Penelitian Pendidikan. Bandung: Alfabeta.

Aminuddin. 2013. Pengantar Apresiaisi Karya Sastra. Bandung: Sinar Baru Algesindo.

Amiri, Sofan dan Iif Khoiru Ahmadi. 2012. Proses Pembelajaran Inovatif dan Kreatif Dalam Kelas. Jakarta: Prestasi Pustakaraya.

Hamdani, 2011. Strategi Belajar Mengajar. Bandung: Pustaka Setia.

Kosasih, E. 2006. Kompetensi Ketatabahasaan dan Kesusasteraan Untuk SMA. Bandung: Adyswara.

Majid, Abdul. 2014. Strategi Pembelajaran. Bandung: PT. REMAJA
ROSDAKARYA. 
Sanjaya, Wina. 2010. Kurikulum dan Surakhmad, Winarno. 2004. Pengantar Pembelajaran. Jakarta: PRENADA MEDIA GROUP. Penelitian Ilmiah Dasar, Metoda, dan Teknik. Bandung: Tarsito.

Siregar, Evelin, dkk. 2010. Teori Belajar dan Thobroni, M. 2015. Belajar dan Pembelajaran. Jakarta: Galia Indonesia.

Pembelajaran. Yogyakarta: AR-RUZZ

Sukardi. 2011. Metodologi Penelitian

Pendidikan. Jakarta: Bumi Aksara.
MEDIA.

Yamin, Moh. 2015. Teori dan Metode Pembelajaran. Malang: Madani. 